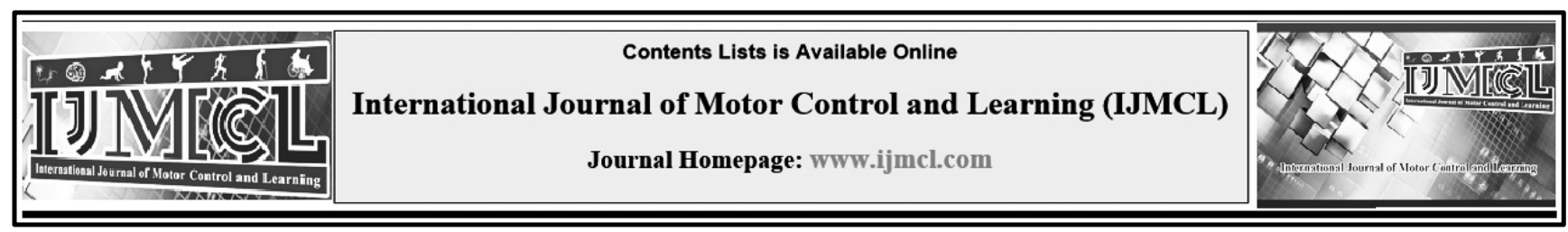

\title{
The Role of Muscle Fibers in the Reactive Balance of Athletes and Non-athletes
}

\author{
Saeed Arsham ${ }^{a *}$, Malihe Sarabandi ${ }^{b}$

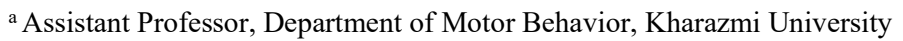 \\ ${ }^{\mathrm{b}}$ Instructor, Department of Sport Sciences, Faculty of Literature \& Human Sciences, University of Zabol
}

\begin{tabular}{|c|c|}
\hline Keywords & Abstract \\
\hline Athlete & Background: The essential part of an athlete's ability is balancing, which involves different \\
\hline Muscle Fiber & $\begin{array}{l}\text { muscular, nervous processes. When creating unexpected disturbances, muscle strength is one } \\
\text { of the essential factors in maintaining a person's balance. }\end{array}$ \\
\hline Reactive Balance & $\begin{array}{l}\text { Objective: The purpose of this study was to determine the relationship between type II } \\
\text { muscle fibers and reactive balance in athlete and non-athlete males. }\end{array}$ \\
\hline $\begin{array}{l}\text { Saeed Arsham, } \\
\text { Email: saeedarsham@yahoo.com }\end{array}$ & $\begin{array}{l}\text { Methods: A total of } 171 \text { volunteers were selected from the statistical population, which } \\
\text { included all male students of Kharazmi University. After eliminating non-qualified } \\
\text { individuals, four groups of } 30 \text { were equally purposeful in terms of the level of performance, } \\
\text { and the type II muscle fiber (i.e., athlete / high percentage, athlete / low percentage, non- } \\
\text { athlete / high percentage, and non-athlete / low percentage) were analyzed as statistical } \\
\text { samples. }\end{array}$ \\
\hline & $\begin{array}{l}\text { The type of muscle fiber was evaluated indirectly by using the Torstenson test on the } \\
\text { Isokinetic Biodex dynamometer. The subjects' balance response was also assessed with a }\end{array}$ \\
\hline Received: 2019/10/18 & Computerized Dynamic Posturography (CDP) using the motor control test. Pearson \\
\hline Accepted: 2020/01/10 & correlation was used to determine the correlation between muscle fiber and balance recovery \\
\hline \multirow[t]{3}{*}{ Published: 2020/02/07 } & $\begin{array}{l}\text { time delay. A multivariate analysis of variance analysis with Bonferroni's post hoc test was } \\
\text { used to compare the mean delay time between athletes and non-athletes with high and low } \\
\text { percentages of type II muscle fiber. }\end{array}$ \\
\hline & $\begin{array}{l}\text { Results: The results showed a significant correlation between the high percentage of type II } \\
\text { muscle intramuscular and reactive equilibrium in athletes and non-athletes with the high } \\
\text { percentage of type II muscle in the anterior axis }(\mathrm{P}=0.005, \mathrm{P}=0.002) \text { and posterior }(\mathrm{P}= \\
0.002 \text { and } \mathrm{P}=0.037) \text { respectively. However, there was no significant correlation between the } \\
\text { low percentage of type II muscle and reactive balance in both groups with a low percentage } \\
\text { of type II muscle fiber }(\mathrm{p} \geq 0.05) \text {. Besides, there was a difference between athletes and non- } \\
\text { athletes with high and low percentages of type II muscle fiber in response to anterior and } \\
\text { posterior axial disturbances }(\mathrm{P}=0.000) \text {. }\end{array}$ \\
\hline & $\begin{array}{l}\text { Conclusion: This study showed a relatively high correlation between the type of muscle in } \\
\text { knee extensors and reactive balance in disturbances of both the posterior and anterior axis. } \\
\text { In particular, a better understanding of the relationship between the type of muscle and } \\
\text { reactive balance is the basis for identifying and identifying individual risks and identifying } \\
\text { strategies to reduce the rate of decline of muscle with type II fiber. }\end{array}$ \\
\hline
\end{tabular}

\section{Introduction}

Balance, which is defined as the ability to control and retrieve the center of mass within the level of reliance (Shumway-Cook \& Woollacott, 2007), includes various neuromuscular processes controlled by sensory afferents, central control processes, and muscular responses (Karimi, Ebrahimi, Kharizi, \& Torkaman, 2008). Due to the effect of many internal and external stimuli on it, it requires a complex organization of various biological systems such as neural conduction, vision, atrial inputs, Proprioception, static reflexes, joint health, muscle strength endurance (YimChiplis \& Talbot, 2000). However, most studies have shown that muscle strength is an important factor in stabilizing and restoring balance through 
various strategies (ankle, knee, pelvis, and gait) when creating unexpected and external disturbances (Orr, 2010). Therefore, one of the factors affecting balance is the muscles' role and, consequently, the muscles around the thighs and knees (Guskiewicz \& Perrin, 1996). Because muscles work around the joints when balancing the body, the role of ankle and thigh strategies is especially important (Punakallio, 2005). The ankle strategy causes the center of gravity to shift by rotating the body around the ankle joint. This condition is inferred from distal activity to the ankle, thigh, and trunk muscle structure's proximal muscles. The thigh strategy controls the center of gravity's movements first by flexion and extension of the thigh and using the activity of the proximal muscles of the thigh and trunk (Horak \& Nashner, 1986). Previously, Nashner et al. (1980) and Dietz et al. (1984) specifically considered thigh and trunk muscle activity as the main factor in participating in rebalancing control. It has also been reported that the rate of compensatory response is important to control balance, and an important aspect depends on the rate of contraction of muscle fibers. It has also been reported that the rate of compensatory response is important for balance control and an important aspect depends on the rate of contraction of muscle fibers (Dietz, Quintern, \& Berger, 1984; L. M. Nashner, 1980). Tang et al. (1998) investigated knee muscle activation's role and showed that knee extensor muscles are activated by balance perturbation with high perturbation amplitude. Therefore, the thigh muscles' activity and the muscles on both sides of the leg and the coordination between the two lower limbs are very important to restore balance (Tang, Woollacott, \& Chong, 1998).

Farber et al. (2002) have shown that muscle activity decreases significantly during the initial standing in response to disturbances. Interpretation of the findings showed that reduced twin muscle activation due to forward disturbances might have stimulated the ankle's plantar flexion, helping maintain balance. Also, the decrease in stability in the ankle's plantar flexion following forward disturbances led to knee flexion and greater activity of the thigh and knee muscles as a reactionary balance strategy, which may be related to the need for a rapid compensatory response depending on muscle structure (Ferber, Osternig, Woollacott, Wasielewski, \& Lee, 2002).

The reactive control strategy is a muscular response to unforeseen disturbances, which in response level of reliance remains unchanged (McComas, 1996). There is some evidence that muscle fibers (for example, a relative percentage of type I or II fibers) can play a key role in the reaction balance for adapting to unexpected disturbances (Putman, Xu, Gillies, MacLean, \& Bell, 2004). For example, in studies confirming the effect of endurance and strength training in athletes, it has been reported that the balance of the strength training group improves faster than the endurance training group. The authors cited differences in muscle fiber composition as an interesting possible explanation for these findings (Johnson \& Woollacott, 2011). Therefore, the improvement in the balance following strength training can be 
attributed to changes in myosin heavy chain profile mechanisms.

Also, Putman et al. (2004), by examining the effects of strength, endurance, and combination exercises on myosin heavy chain and muscle fiber distribution, concluded that strength training leads to a change in the type of muscle fiber in trained muscles in young and elderly. This occurs during a relative increase in the myosin heavy chain (the second type of fast-twitch fibers) (Putman et al., 2004). Over (2010), in a review study on the role of muscle weakness in posture instability and determining the relationship between muscle weakness and balance injuries and stated that strength training and muscle strength leads to improved balance. However, the evidence for their effectiveness and the reason for the relationship between muscle role and balance function is unclear (Orr, 2010). For example, Paterno et al. (2009) examined the role of lower limb strength and postural stability in performing the Star Rotation Test (SEBT) and showed that the introverted strength of knee extensions did not predict individuals' performance on the SemiDynamic Star Rotation Equilibrium Test (Paterno, Schmitt, Ford, \& Hewett, 2009) While according to the study of Loki et al. (2013) more strength of knee extensions can increase the stability of oneway dynamics in team athletes (Lockie, Schultz, Callaghan, \& Jeffriess, 2013).

However, Johnson and Wolakat (2011) emphasize the structural differences in muscles and their response to the type of exercise or level of individuals' performance in terms of whether or not they are athletes. They showed the effectiveness of strength training compared to endurance training in restoring balance to rapid perturbations. In their opinion, due to the significant difference between slow and fast muscle fibers in terms of crosssectional area and number of sarcomeres, the force is normalized to the cross-sectional area, the two types of filaments cannot produce the same force. Unlike specific stresses, filament type and shortening rate are related due to the presence of fast or slow isoforms of myosin heavy chain molecules responsible for approximately three to four times the difference in maximum shortening rate (Johnson \& Woollacott, 2011).

On the other hand, Frontera et al. (2014) showed that type II fibers have a larger crosssectional area than type I fibers and are more adapted for sudden and stronger contraction as well as repetitive movements. Still, these fibers wear out quickly, and eventually, they lead to a decrease in balance (Frontera \& Ochala, 2015). In contrast, Miller et al. (2015) examined the relationship between muscle fiber type and reactive balance in young college students. They found a direct relationship between the time balance and the percentage of type II rapid muscle contraction (Miller, Heath, Dickinson, \& Bressel, 2015). Boysen et al. (2015) obtained intermediate results by considering the type of contraction and the muscles involved, which increases the need for research. By studying the relationship between extroverted power and strength with dynamic balance, he found that balance test scores correlated highly with the extrovert power of non- 
superior knee extensor in players, but no such correlation was observed in the knee flexors, and dynamic balance performance on the dominant leg was better (Booysen, Gradidge, \& Watson, 2015).

As observed, studies that determine the role of knee extensor muscle strength in controlling balance show conflicting results. In addition, very little attention has been paid to muscle fibers' role in relation to factors affecting or determining the balance. Few studies have encountered limitations, such as not considering the level of performance of subjects or their other characteristics. Therefore, this study aimed to determine the relationship between muscle fiber type and reactive balance of athletes and non-athletes.

\section{Method}

The present study is a semi-experimental design. The statistical population included male students of Kharazmi University, from which 117 people (19 to 25 years old) were selected voluntarily. After eliminating the unqualified individuals, four groups of 30 people were equated purposefully in terms of performance level and muscle fiber (i.e., athlete / high fiber percentage, athlete / low fiber percentage, non-athlete / high fiber percentage, and non-athlete / low fiber percentage).

Athletes exercised at least four sessions per week, one or one and a half hours per session at the university level (AMIRI \& MOGHARABI, 2013). Their type of sports activity was not controlled due to the impossibility of accessing a larger sample size and matching all conditions. Inclusion criteria included: filling consent, the natural arch of the foot, no history of balance injury, no history of ankle sprains, normal body mass index, no history of dislocation and fracture of the lower extremities, no medication, lack of balance problems, and superior right foot. A medical history form was used to identify physical problems such as lower limb injuries or vision and atrial problems (Acevedo \& Starks, 2011). The superior foot was also identified by asking the question, "with which foot do you hit the ball?"

\section{Procedure}

After inviting individuals to participate in the study, consent and medical records forms were distributed among them. Then, their weight was measured to the nearest hundred kilograms (with the least clothing) and their height standing on the wall with a tape meter. After calculating the body mass index according to the study of Cal et al. (2003), individuals in the range between 18.5 to 24.9 were selected (Calle, Rodriguez, WalkerThurmond, \& Thun, 2003). A tape measure was used to calculate the thigh index, i.e. the ratio of leg length to thigh length multiplied by 100 (Ackland, Elliott, \& Bloomfield, 2009), and a ruler was used to measure the amount of arch of the sole of the foot while sitting and standing.

Other characteristics such as flat feet and hamstring muscle strength to quadriceps other characteristics such as flat feet and the ratio of hamstring muscle strength to quadriceps were specified as follows. Koteh et al.'s (2005) method was used to diagnose flat feet, and the amount of 
navicular bone loss was measured in millimeters. The participants who had a navy drop of 5 to $9 \mathrm{~mm}$ were considered to have normal plantar fasciitis (Cote, Brunet, II, \& Shultz, 2005). The maximum repetition (1RM) method was used to evaluate the hamstring to quadriceps strength ratio $(\mathrm{H} / \mathrm{Q})$. That is, the amount of isotonic strength of the quadriceps muscles was divided into the amount of isotonic strength of the hamstring muscles (Acevedo \& Starks, 2011). The type of muscle fiber in right knee extensions was indirectly calculated as a percentage using Thorstenson test, which included a maximum of 50 isokinetic extensions (180 degrees per second) on the Biodex isokinetic strength meter. An isokinetic strength meter is a device that measures the output strength of quadriceps muscles. This test was first developed in 1970 by Alf Thorstenson and is calculated as follows:

$$
\left[\frac{\text { Average of first } 3 \text { repetitions }- \text { Average of last } 3 \text { repetitions }}{\text { Average of first } 3 \text { repetitions }} \times 100 \times 0.9\right]+5.2
$$

The number obtained is a percentage of fasttwitch fibers; the percentage of slow-twitch fibers was also obtained by comparing the percentage of slow-twitch fibers from 100 (Lovitt \& Speraw, 2004).

The balanced reaction of individuals was evaluated by a dynamic computerized choreography device using a motion control reference test (MCT). Balance recovery time (in milliseconds) was calculated by measuring a sudden change in the center of force to maintain a standing position after perturbations in milliseconds on the anterior-posterior axes.

For the Thorstenson test before data collection, participants were told how to do the activity and advised to refrain from strenuous exercise for 24 hours before the test. The person was first asked to warm up for 5 minutes by jogging and stretching. He was then asked to sit on the isokinetic machine. The extension lever was adjusted for him. In the next step, while announcing the readiness, the person was asked to perform 50 knee extension movements (resistance in all movements). There was no need to count repetitions, and the device determined the percentage of muscle fibers by measuring the output power of the quadriceps muscle. The duration of this test was 20 minutes for each person (Lovitt \& Speraw, 2004). Balance recovery was performed 24 to 72 hours after the Thorstenson test.

To evaluate the balance reactions, using dynamic computerized choreography, participants were stay on the machine's power platform without shoes. After fastening the seat belts, the person's legs were adjusted to the designated location (center of zero forces), and they were told not to move their legs. While looking straight ahead with their eyes open and their heads and faces straight, they were asked to maintain their balance as much as possible after the disturbances caused by the 
postchromographic device in the anterior and posterior directions. NeuroCom software, based on the subjects' initial information, normalized the movement distance of the support surface with the participants' height to reach the required speed and amplitude of the center of gravity. This allows the results of all participants to be compared. Delay in motor responses was calculated and measured in milliseconds in the anterior and posterior directions during turbulence. During the test, the test would be stopped if participants touched the device's wall or the tester who was present for support. Since the height of people can be different from each other, the average speed of movement on the device is proportional to their height for short height (12.2 $\mathrm{cm} / \mathrm{s})$, for medium height $(25.4 \mathrm{~cm} / \mathrm{s})$, and tall people $(34.3 \mathrm{~cm} / \mathrm{s})$ (18). Sudden changes in the center of gravity after turbulence were calculated in milliseconds, and all data were analyzed using SPSS software version 20 at a significance level of 0.05 .

\section{Results}

After examining the normality of the data by Shapiro-Wilk test and homogeneity of variances with the Loon test, Pearson correlation was used to determine the relationship between the percentage of type II muscle fibers and the delay in balance recovery time in the right leg of the participants. To compare the mean latency between athletic and non-athletic participants with a high percentage of type II muscle fibers and individuals with a lower percentage, multivariate analysis of variance with the Bonferroni post hoc test was used.

Table 1. Mean (Standard Deviation) of the variables of the four groups.

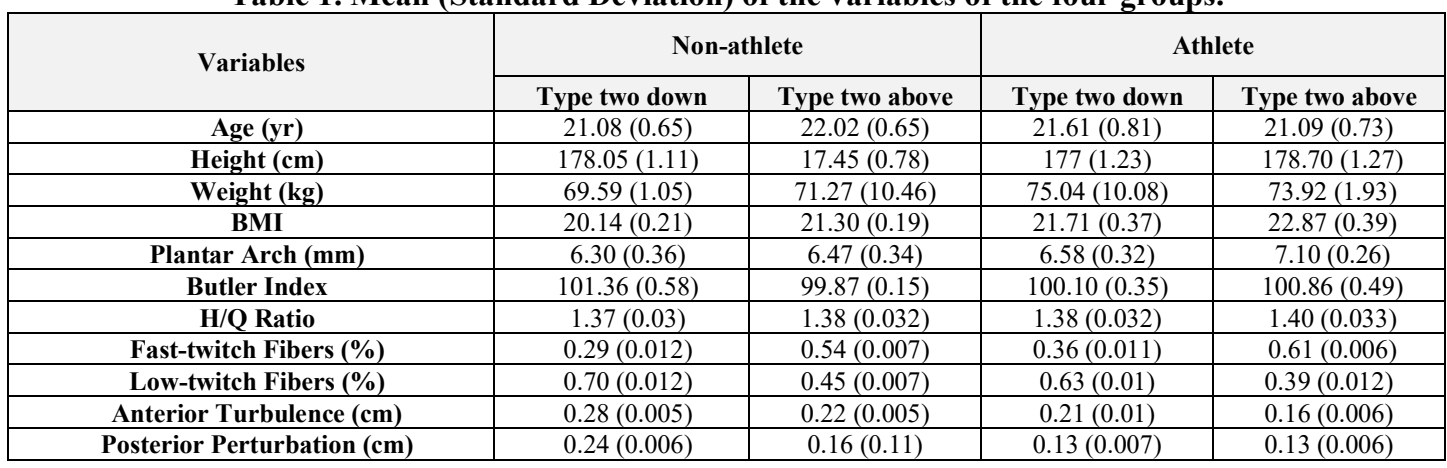

Table 2: Correlation results of type II muscle fiber and balance recovery time (COP) in athletes and non-athletes.

\begin{tabular}{|c|c|c|c|c|c|}
\hline \multirow{2}{*}{$\begin{array}{c}\text { Percent of } \\
\text { muscle fiber }\end{array}$} & \multirow{2}{*}{$\begin{array}{c}\text { Balance } \\
\text { perturbation }\end{array}$} & \multicolumn{2}{|c|}{$\begin{array}{c}\text { The correlation } \\
\text { coefficient }\end{array}$} & \multicolumn{2}{|c|}{$\mathbf{p}$} \\
\hline & & Athlete & $\begin{array}{l}\text { Non- } \\
\text { athlete }\end{array}$ & Athlete & $\begin{array}{c}\text { Non- } \\
\text { athlete }\end{array}$ \\
\hline \multirow{2}{*}{$\begin{array}{c}\text { High } \\
\text { percentage II }\end{array}$} & $\begin{array}{c}\text { Anterior } \\
\text { turbulence }\end{array}$ & -0.80 & -0.70 & 0.005 & 0.002 \\
\hline & $\begin{array}{l}\text { Posterior } \\
\text { turbulence }\end{array}$ & -0.70 & -0.66 & 0.002 & 0.037 \\
\hline \multirow{2}{*}{$\begin{array}{c}\text { low } \\
\text { percentage II }\end{array}$} & $\begin{array}{c}\text { Anterior } \\
\text { turbulence }\end{array}$ & -0.33 & -0.29 & 0.352 & 0.551 \\
\hline & $\begin{array}{l}\text { Posterior } \\
\text { turbulence }\end{array}$ & -0.53 & -0.35 & 0.114 & 0.184 \\
\hline
\end{tabular}


According to the results of Table 2, there is a significant relationship between a high percentage of type II muscle fibers and balance recovery time in athletic boys as well as in non-athlete boys, in both anterior and posterior axis disorders $(\mathrm{p} \leq 0.05)$. It can be concluded that in individuals with a high percentage of type II muscle fibers, the response time to disturbances was reduced.
However, there was no significant relationship between the low percentage of type II muscle fibers and balance recovery time in athlete boys and nonathlete boys in the anterior and the posterior axis $(p \geq 0.05)$. Therefore, the response time to disturbances in the above two axes was increased in athlete and non-athlete boys with a low percentage of type II muscle fibers.

Table 3: Results of multivariate analysis of variance of reactive balance in anterior and posterior perturbations.

\begin{tabular}{|c|c|c|c|c|c|c|}
\hline & Source & $\begin{array}{c}\text { Sum of } \\
\text { Squares }\end{array}$ & df & $\begin{array}{c}\text { Average of } \\
\text { Squares }\end{array}$ & F & P \\
\hline \multirow{4}{*}{$\begin{array}{c}\text { Anterior } \\
\text { Turbulence }\end{array}$} & Group & 0.041 & 1 & 0.041 & 74.851 & 0.000 \\
\cline { 2 - 7 } & Fiber Type & 0.034 & 1 & 0.034 & 61.474 & 0.000 \\
\cline { 2 - 7 } & Interaction & 0.016 & 1 & 0.016 & 0.164 & 0.687 \\
\hline \multirow{3}{*}{$\begin{array}{c}\text { Posterior } \\
\text { Turbulence }\end{array}$} & Group & 0.043 & 1 & 0.043 & 62.657 & 0.000 \\
\cline { 2 - 7 } & Fiber Type & 0.015 & 1 & 0.015 & 21.647 & 0.000 \\
\cline { 2 - 7 } & Interaction & 0.016 & 1 & 0.016 & 22.878 & 0.000 \\
\hline
\end{tabular}

According to the results of Table 3, the main effect of the group and the main effect of the type of muscle fibers on the anterior axis turbulence is significant $(\mathrm{p} \leq 0.05)$. In contrast, the interaction between the group and the muscle fiber is not significant $(\mathrm{p} \leq 0.05)$. Due to the lack of significance of the interaction, there is no significant difference between athletes and non-athletes with a high percentage of the type II muscle fibers and a low percentage of the type II muscle fibers ( $p \geq 0.05$ ).

Also, the group's main effect and the main effect of the fiber type on posterior axis turbulence are significant $(\mathrm{p} \leq 0.05)$. Also, the interaction between the group and the muscle fiber is significant $(p \leq 0.05)$. Therefore, due to the significant interaction between athletes and nonathletes with a high percentage of the type II muscle fibers and a low percentage of the type II muscle fibers, Bonferroni post hoc test was used to compare pairs between groups which the results are reported in Table 4. 
Table 4: Bonferroni test results related to pair comparison of groups for reactive balance in posterior perturbation.

\begin{tabular}{|c|c|c|c|}
\hline & Group & $\begin{array}{c}\text { Difference in } \\
\text { Averages }\end{array}$ & $\mathbf{P}$ \\
\hline \multirow{3}{*}{$\begin{array}{l}\text { Athlete with High } \\
\text { Percentage }\end{array}$} & $\begin{array}{l}\text { Athlete with Low } \\
\text { Percentage }\end{array}$ & -0.117 & 0.000 \\
\hline & $\begin{array}{l}\text { Non-athlete with } \\
\text { Low Percentage }\end{array}$ & -0.350 & 0.000 \\
\hline & $\begin{array}{l}\text { Non-athlete with } \\
\text { High Percentage }\end{array}$ & -0.98 & 0.000 \\
\hline \multirow{2}{*}{$\begin{array}{l}\text { Athlete with Low } \\
\text { Percentage }\end{array}$} & $\begin{array}{l}\text { Non-athlete with } \\
\text { High Percentage }\end{array}$ & 0.027 & 1.000 \\
\hline & $\begin{array}{l}\text { Non-athlete with } \\
\text { Low Percentage }\end{array}$ & -0.101 & 0.000 \\
\hline $\begin{array}{l}\text { Non-athlete with } \\
\text { High Percentage }\end{array}$ & $\begin{array}{l}\text { Non-athlete with } \\
\text { Low Percentage }\end{array}$ & -0.180 & 0.000 \\
\hline
\end{tabular}

\section{Discussion and Conclusion}

Athletes and non-athletes with a high percentage of type II muscle fibers were able to have faster recovery time with disturbances in both the posterior and anterior axes. Miller et al. (2015) reported a significant negative correlation between the percentage of type II muscle fibers in the knee extensors to posterior disturbances. Still, they did not find a correlation between the percentage of this type of muscle fibers in the knee extensors to the anterior disturbances (Miller et al., 2015). The results of the present study in the posterior axis are completely consistent with their study. When experiencing an unpredictable disturbance at the support level, the muscles around the knees and thighs will continue to work continuously. Rang et al. (1998), in one study about low-velocity posterior perturbations $(5 \mathrm{~cm} \mathrm{/} \mathrm{s)} \mathrm{and} \mathrm{high}$ velocities $(55 \mathrm{~cm} / \mathrm{s})$ showed that the knee extensor joints at high intensities are of special importance for restoring balance against posterior disturbances (Runge, Shupert, Horak, \& Zajac, 1998). The present study results are also consistent with Rang's findings because the role of knee extensor muscles due to having a higher percentage of type II muscle fiber is particularly important in determining the relationship between the type of muscle fiber and reactive balance in response to posterior axis disturbances. The present study on anterior perturbation also confirms the findings of Farber et al. (2002). They showed that the decrease in stability during the initial standing following anterior disturbances leads to knee flexion related to the rapid compensatory response depending on the muscle structure (Ferber et al., 2002). Therefore, it seems that knee extensions are significantly activated to restore balance following anterior and posterior disturbances. This study's results are also consistent with the findings of $\mathrm{Yu}$ et al. (2001) on the activity of knee flexor muscles in the posterior axis (You, Chou, Lin, \& Su, 2001). Therefore, a possible significant cause of the relationship between the type of muscle fiber and the reaction balance in the anterior and posterior axes is the high rate of fast-twitch muscles' responses to these disturbances, which is completely consistent with the study of Frontera et al. (2014). They stated that type II fibers are more 
adaptable for sudden and stronger contractions (Frontera \& Ochala, 2015). Besides, the greater myosin heavy chain isoforms in fast-twitch muscles (Gabriel, Kamen, \& Frost, 2006), and the larger volume of the sarcoplasmic reticulum of these fibers lead to faster shortening of fast-twitch muscles in restore balance and usually less response time. Therefore, it seems that the main reason for faster recovery to turbulence in these two axes is to have a higher percentage of type II muscle fibers in these subjects. Tang et al. (1998) showed that the knee's extensor muscles are activated in response to a high amplitude of turbulence (Tang et al., 1998). Therefore, when the ankle cannot exert the torque required to restore balance against larger disruptive forces, the knee and thigh joint strategy is used to maintain balance (L. Nashner, 1997).

However, in the low percentage of type II muscle fibers, both athletes and non-athletes could not have faster recovery time with turbulence in both the posterior and anterior axes. Slow-twitch fibers take 110 milliseconds (versus 50 milliseconds for fast-twitch fibers) to reach peak stress, which in turn leads to different response times in athletes and even non-athletes. Also, slowtwitch fibers with more myosin light chain isoforms are involved in long-term and repetitive contractions, and the response rate provided by them is less than myosin heavy chain. Non-athletes with a lower percentage of type II muscle fibers responded to both the anterior and posterior axes' perturbations with greater time to restore balance. Therefore, it seems that the probable reason for the lack of a significant relationship between type II muscle fibers and reactive balance in non-athletes with a low percentage of type II muscle fibers is the higher percentage of type I muscle fibers in these individuals, which resulted in an increase in balance recovery time following perturbations in both the anterior and posterior axes. Also, type I fibers, due to having less contractile proteins, higher mitochondrial volume, smaller crosssection, and lower shortening rate are activated later when there is an imbalance compared to type II fibers longer to deal with perturbations. The probable reason for such results is the lower percentage of type II muscle fibers in athletes, which led to an increase in response time in both anterior and posterior axes.

The results of this study show that there is a difference between athletes and non-athletes with high and low percentages of the second type of muscle fiber in response to disturbances of both anterior and posterior axes, but the interaction of fiber type and group in the anterior axis was not significant. While in the posterior axis, the main effect of the type of muscle fiber is significant. In addition, the findings showed that in the posterior axis, the interaction between the group and the type of muscle fiber in perturbations is significant.

One reason for the difference between athletes and non-athletes is the training factor. The ability to produce the right response and then adapt to persistent balance disturbances requires proper exercise and improved coordination between nerve and muscle (Ferber et al., 2002). Studies conducted in most people who were less active than active 
people showed changes in neuromuscular properties, including upright muscles involving balance control. These restrictions may include increased fluctuations and decreased number of type II motor units compared to type I motor units in sedentary adults. Strength training (Guskiewicz \& Perrin, 1996) can slow down the decline of many of these constraints (Forrest, Zmuda, \& Cauley, 2007; Lee, Cheung, Qin, Tang, \& Leung, 2006). In addition, strength training promotes hormonal and neuromuscular adaptation within a few months (Cardinale \& Wakeling, 2005; Delecluse, Roelants, \& Verschueren, 2003). Strength athletes develop hypertrophy, especially in type II muscle fibers, using progressive training and high-speed running. This training program's specificity has led to a special adaptation in the nervous system that allows more and faster use of motor units (Gabriel et al., 2006). These changes can lead to faster initial muscle coordination and a greater range of muscle contractions during the performance of many motor skills, including postural skills such as balance recovery (Johnson \& Woollacott, 2011). Therefore, the reason for the difference between athletes and non-athletes is related to the adaptations resulting from training. The level of physical activity reduces the rate of decline of type II muscle fibers in the athlete group, which can help balance disorders recover more quickly. The present study results confirm the findings of Baron et al. (2011) regarding the difference between individuals in terms of balance due to the effect that systems create (Barone et al., 2011). In the present study, both groups of athletes were homogeneous in terms of muscle height and strength, and the results showed that the balance of athletes with a high percentage of type II muscle fibers was better than the non-athlete group with a lower percentage of type II muscle fibers. The first group had a faster recovery time in response to disturbances, indicating the importance and prominent role of type II muscle fibers. Also, a better balance in athletes than non-athletes can be due to an increase in sensory-body system information and recall of neuromuscular units. The results of this study in the field of differences between athletes and nonathletes are consistent with the study of Baron et al. (2011) and Dawlin et al. (2004) (Barone et al., 2011; Davlin, 2004). On the other hand, in the nonathlete group, a lower relative share of type II fibers leads to an increase in balance recovery time. Also, it seems that the main reason for the significance of the main effect of the type of fiber with high and low percentages is physiological differences between different types of fibers. This major difference can be in the level of muscle crosssection, the rate of release of acetylcholine from nerve terminals, different forms of myosin ATPase, different mitochondrial volume, which is present in type II fibers compared to type I fibers. One of the main limitations of this study was the difficulty of accessing a larger volume of samples that could be separated and homogenized according to the type of exercise activity. Classifying the type of sports activity will help to better explain the results and therefore it is recommended to pay attention to this issue in future research. According to the results of the present study, it can be said that the relationship 
between the type of muscle fiber and reactive balance may be of good use for the elderly. Because it has been proven that with increasing age, muscle mass decreases and this decrease in muscle mass is largely related to the loss and deterioration of type II muscle fibers compared to type I muscle fibers. A decrease in type II muscle fibers not only reduces the ratio of the ability to produce muscle force, even, it leads to limiting functional tasks, such as climbing stairs or moving away from obstacles quickly. In summary, the results of this study showed that there is a relatively high correlation between the type of muscle fibers in the knee extensions and the reaction balance in perturbations of both the posterior and anterior axes. In particular, a better understanding of the relationship between muscle fiber type and reactive balance may be the basis for identifying and introducing individual hazards as well as determining exercise strategies (doing power training to slow the decline of type II muscle fibers) and reducing the risk of falls in the elderly population.

\section{References}

1. Acevedo, E. O., \& Starks, M. A. (2011). Exercise testing and prescription lab manual: Human Kinetics.

2. Ackland, T. R., Elliott, B., \& Bloomfield, J. (2009). Applied anatomy and biomechanics in sport: Human Kinetics.

3. AMIRI, K. M., \& MOGHARABI, M. M. (2013). Effect of different physical activity levels on the static and dynamic balance of dominant and non-dominant legs in females.

4. Barone, R., Macaluso, F., Traina, M., Leonardi, V., Farina, F., \& Di Felice, V. (2011). Soccer players have a better standing balance in nondominant one-legged stance. Open access journal of sports medicine, 2, 1.

5. Booysen, M. J., Gradidge, P. J.-L., \& Watson, E. (2015). The relationships of eccentric strength and power with dynamic balance in male footballers. Journal of sports sciences, 33(20), 2157-2165.

6. Calle, E. E., Rodriguez, C., Walker-Thurmond, K., \& Thun, M. J. (2003). Overweight, obesity, and mortality from cancer in a prospectively studied cohort of US adults. New England Journal of Medicine, 348(17), 1625-1638.

7. Cardinale, M., \& Wakeling, J. (2005). Whole body vibration exercise: are vibrations good for you? British journal of sports medicine, 39(9), 585-589.

8. Cote, K. P., Brunet, M. E., II, B. M. G., \& Shultz, S. J. (2005). Effects of pronated and supinated foot postures on static and dynamic postural stability. Journal of athletic training, 40(1), 41.

9. Davlin, C. D. (2004). Dynamic balance in high level athletes. Perceptual and motor skills, 98(3_suppl), 11711176.

10. Delecluse, C., Roelants, M., \& Verschueren, S. (2003). Strength increase after whole-body vibration compared with resistance training. Medicine \& Science in Sports \& Exercise, 35(6), 1033-1041.

11. Dietz, V., Quintern, J., \& Berger, W. (1984). Corrective reactions to stumbling in man: functional significance of spinal and transcortical reflexes. Neuroscience letters, 44(2), 131-135.

12. Ferber, R., Osternig, L. R., Woollacott, M. H., Wasielewski, N. J., \& Lee, J.-H. (2002). Reactive balance adjustments to unexpected perturbations during human walking. Gait \& posture, 16(3), 238-248.

13. Forrest, K. Y., Zmuda, J. M., \& Cauley, J. A. (2007). Patterns and correlates of muscle strength loss in older women. Gerontology, 53(3), 140-147.

14. Frontera, W. R., \& Ochala, J. (2015). Skeletal muscle: a brief review of structure and function. Calcified tissue international, 96(3), 183-195.

15. Gabriel, D. A., Kamen, G., \& Frost, G. (2006). Neural adaptations to resistive exercise. Sports Medicine, 36(2), 133-149.

16. Guskiewicz, K. M., \& Perrin, D. H. (1996). Research and clinical applications of assessing balance. Journal of Sport Rehabilitation, 5(1), 45-63.

17. Horak, F. B., \& Nashner, L. M. (1986). Central programming of postural movements: adaptation to altered support-surface configurations. Journal of neurophysiology, 55(6), 1369-1381.

18. Johnson, T. K., \& Woollacott, M. H. (2011). Neuromuscular responses to platform perturbations in power-versus endurance-trained athletes. Perceptual and motor skills, 112(1), 3-20.

19. Karimi, N., Ebrahimi, I., Kharizi, S., \& Torkaman, G. (2008). Reliability of postural balance evaluation using the biodex balance system in subjects with and without low back pain. Journal of Postgraduate Medical Institute (Peshawar-Pakistan), 22(2).

20. Lee, W.-S., Cheung, W.-H., Qin, L., Tang, N., \& Leung, K.-S. (2006). Age-associated Decrease of Type IIA/B Human Skeletal Muscle Fibers. Clinical Orthopaedics and Related Research (1976-2007), 450, 231-237.

21. Lockie, R. G., Schultz, A. B., Callaghan, S. J., \& Jeffriess, M. D. (2013). The effects of isokinetic knee extensor and flexor strength on dynamic stability as 
measured by functional reaching. Isokinetics and Exercise Science, 21(4), 301-309.

22. Lovitt, M., \& Speraw, J. (2004). Exercise for Your Muscle Type: The Smart Way to Get Fit: Basic Health Publications, Inc.

23. McComas, A. J. (1996). Skeletal muscle: form and function: Champaign, IL: Human Kinetics.

24. Miller, A. I., Heath, E. M., Dickinson, J. M., \& Bressel, E. (2015). Relationship between muscle fiber type and reactive balance: a preliminary study. Journal of motor behavior, 47(6), 497-502.

25. Nashner, L. (1997). Physiology of balance, with special reference to the healthy elderly. Gait disorders of aging: falls and therapeutic strategies, 37-53.

26. Nashner, L. M. (1980). Balance adjustments of humans perturbed while walking. Journal of neurophysiology, 44(4), 650-664.

27. Orr, R. (2010). Contribution of muscle weakness to postural instability in the elderly. Eur J Phys Rehabil Med, 46(2), 183-220.

28. Paterno, M., Schmitt, L., Ford, K., \& Hewett, T. (2009). CONTRIBUTION OF LOWER EXTREMITY STRENGTH AND POSTURAL STABILITY TO PERFORMANCE ON THE STAR EXCURSION BALANCE TEST: SPL01. journal of Orthopaedic \& Sports Physical, 39(1).

29. Punakallio, A. (2005). Balance abilities of workers in physically demanding jobs: With special reference to firefighters of different ages. Journal of Sports Science and Medicine, 4(8), 1-47.

30. Putman, C. T., Xu, X., Gillies, E., MacLean, I. M., \& Bell, G. J. (2004). Effects of strength, endurance and combined training on myosin heavy chain content and fibre-type distribution in humans. European journal of applied physiology, 92(4-5), 376-384.

31. Runge, C., Shupert, C., Horak, F., \& Zajac, F. (1998). Role of vestibular information in initiation of rapid postural responses. Experimental brain research, 122(4), 403-412.

32. Shumway-Cook, A., \& Woollacott, M. H. (2007). Motor control: translating research into clinical practice: Lippincott Williams \& Wilkins.

33. Tang, P.-F., Woollacott, M. H., \& Chong, R. K. (1998). Control of reactive balance adjustments in perturbed human walking: roles of proximal and distal postural muscle activity. Experimental brain research, 119(2), 141-152.

34. Yim-Chiplis, P. K., \& Talbot, L. A. (2000). Defining and measuring balance in adults. Biological research for nursing, 1(4), 321-331.

35. You, J.-Y., Chou, Y.-L., Lin, C.-J., \& Su, F.-C. (2001). Effect of slip on movement of body center of mass relative to base of support. Clinical Biomechanics, 16(2), 167-173. 